\title{
Thickness and film stress effects on the martensitic transformation temperature in equi-atomic NiTi thin films
}

\author{
Xi Wang ${ }^{1, *}$, Joost J. Vlassak ${ }^{2}$ \\ ${ }^{1}$ School of Mechanical, Electronic and Control Engineering, Beijing Jiaotong University, \\ Beijing 100044, China \\ ${ }^{2}$ School of Engineering and Applied Sciences, Harvard University, Cambridge, MA 02138, \\ USA
}

\begin{abstract}
This paper presents the results of an experimental study of the transformation behavior and its thickness dependence of submicron Ni-50.5at \% Ti thin films on substrates. Measurements were performed on thin films with a microstructure that consisted of pancake-like grains with aspect ratios in excess of 50:1 in order to minimize grain-imposed constraints. The effect of the residual stress on the martensite transformation behavior was evaluated by using different substrate materials covering a range of thermal expansion coefficients. If the thermal stress in the austenite phase exceeds $\sim 300 \mathrm{MPa}$, the martensitic transformation occurs in a one-step process from B2 $\rightarrow$ B19', while films with a lower stress follow a two-step transformation of $\mathrm{B}_{2} \rightarrow \mathrm{R}-$ phase $\rightarrow$ B19'. The slope of the stress-temperature curve during the B2 $\rightarrow$ B19' transformation is much larger than the equilibrium value and trends up with decreasing film thickness. For films less than $400 \mathrm{~nm}$ in thickness, the transformation temperature decreases rapidly with decreasing film thickness. Cross-sectional TEM analysis reveals small composition shifts in the immediate vicinity of the film interfaces, but not in the bulk of the films, ruling out any composition effects
\end{abstract}

\footnotetext{
${ }^{*}$ Corresponding author. Tel./fax: +86 1051683195

E-mail address: wangxi@bjtu.edu.cn (X. Wang)
} 
on the transformation temperature. A simple micro-mechanics model is used to explain the observed size effects.

Keywords: Shape memory alloy thin films; Martensitic phase transformation; Substrate constraint; Thickness effect. 


\section{Introduction}

Shape memory alloy (SMA) thin films, especially those based on NiTi, have been studied extensively over the last few decades because they are promising candidate materials for actuators in microelectromechanical systems (MEMS) (Ishida et al., 1995; König et al., 2011; McCluskey et al., 2011; Miyazaki and Ishida, 1994; Tomozawa et al., 2009; Wolf and Heuer, 1995). Several reviews of SMA process technology can be found in the literature (Fu et al., 2004; Ishida and Martynov, 2002; Winzek et al., 2004), while a detailed summary of the physical metallurgy of NiTi-based SMAs has been published by Otsuka and Ren (Otsuka and Ren, 2005). The high degree of miniaturization of current and future micro-devices has initiated efforts to develop actuators based on very thin SMA films. Use of SMA films in these applications requires a good understanding of the effect of film thickness on their transformation behavior. The martensitic transformation in an SMA material involves a series of complicated morphological changes in which martensite variants are formed to accommodate the large transformation strains (Otsuka and Wayman, 1999). The energy cost associated with the compatibility strains and with the formation of the various interfaces naturally resists the martensitic transformation, an effect one would expect to become more important with decreasing length scale.

Models for the phase transformation behavior of an SMA film constrained by a substrate have been discussed at length in the literature (Roytburd, 1998a, b; Roytburd et al., 1998; Roytburd and Slutsker, 2001, 2002). In particular, Roytburd and co-workers proposed a model for the behavior of a single crystal SMA film on a substrate based on the thermodynamics of constrained transformations (Roytburd et al., 1998). However, few systematic experimental studies on constrained transformation of SMA films have been reported. Fu et al. (Fu et al., 2006) 
used the substrate curvature technique to study the effects of film thickness on the transformation of $\mathrm{Ni}_{49.8} \mathrm{Ti}_{50.2}$ films on silicon substrates. They claimed that a minimum film thickness of approximately $100 \mathrm{~nm}$ is required to show a martensitic transformation because of surface oxidation and inter-diffusion of film and substrate. König et al. (König et al., 2012) reported on the film thickness dependence of the $\mathrm{B} 2 \rightarrow \mathrm{B} 19$ martensitic transformation in $\mathrm{Ti}_{51} \mathrm{Ni}_{38} \mathrm{Cu}_{11}$ thin films using the four probe resistivity method. They found that the transformation temperature initially decreases with film thickness because of the decreasing grain size, but increases sharply for thicknesses below $100 \mathrm{~nm}$ because of the high tensile stresses in the films.

There are several factors that complicate an experimental investigation of the transformation behavior of SMA thin films on substrates. The stress level in the films varies with film thickness and changes during the measurement because of thermal mismatch between film and substrate. NiTi thin films are usually deposited by means of sputtering. Unless the deposition is performed at elevated temperature, sputtered NiTi films are amorphous in as-deposited state and need to be crystallized with an appropriate heat treatment (Wolf and Heuer, 1995). The crystallization kinetics of NiTi thin films depends on the film thickness and slows down significantly for very thin films (Wang et al., 2008). The heat treatment may result in different grain sizes for films with different thicknesses and, if the films are very thin, surface oxidation and interfacial reactions between film and underlying substrate material (typically $\mathrm{Si}$ or $\mathrm{SiO}_{2}$ ) during the heat treatment cannot be neglected. Clearly, film stress, film thickness, grain size, surface oxidation, and interfacial reaction all play a role in the transformation behavior of SMA films making interpretation of the transformation behavior a challenge.

This paper presents the results of an experimental study of the transformation behavior of submicron near-equiatomic NiTi films supported by a substrate. In this study we have tried to 
overcome the issues mentioned above by using substrates made of a range of different materials. By controlling the thermal mismatch between film and substrate, it is possible to independently evaluate the effects of both film thickness and film stress on the martensitic transformation. The heat treatment of the near-equiatomic sputtered NiTi films used in the study was tailored to maximize the NiTi grain size in the films and thus eliminate any grain size effect. Oxidation and interfacial reactions were minimized by sandwiching the NiTi films between $\mathrm{SiN}_{\mathrm{x}}$ layers.

\section{Experimental}

Near-equiatomic NiTi thin films with thicknesses of 910, 470, 370, 290 and $190 \mathrm{~nm}$ were deposited by means of DC magnetron sputtering using NiTi and Ti targets in a confocal setup (Shih et al., 2001). The base pressure of the deposition chamber was below $5 \times 10^{-8}$ Torr and the Ar working pressure was 1.5 mTorr for all depositions. The nominal target-substrate distance was $100 \mathrm{~mm}$ resulting in a deposition rate of approximately $12 \mathrm{~nm} / \mathrm{min}$. The substrates were rotated at a speed of 20 RPM to improve the composition and thickness uniformity of the films. The chemical composition of the as-deposited films was measured to be Ni-50.5 \pm 0.2 at. \% $\mathrm{Ti}$ by means of Rutherford backscattering spectrometry (RBS). The NiTi films were deposited onto four different types of substrates to control the stress in the films: Corning glass, Pyrex 7740 glass, (001) single-crystal silicon, and fused quartz, in order of increasing thermal mismatch with

NiTi. Prior to the NiTi deposition, all substrates were coated with a $\operatorname{SiN}_{x}$ film $(\sim 50 \mathrm{~nm}$ in thickness) to ensure that the surfaces presented to the NiTi were identical for the different types of substrates. Immediately after deposition, a second layer of $\operatorname{SiN}_{\mathrm{x}}(\sim 30 \mathrm{~nm}$ in thickness $)$ was coated onto the NiTi film surface to prevent oxidation of the films during the heat treatment. The $\mathrm{SiN}_{\mathrm{x}}$ films were deposited with a NEXX Cirrus-150 plasma-enhanced chemical vapor deposition 
(PECVD) system and the deposition conditions are listed in Table 1. The amorphous asdeposited NiTi films were crystallized by annealing them at a temperature of $450^{\circ} \mathrm{C}$ for 20 minutes in a vacuum furnace with a base pressure less than $5 \times 10^{-7}$ Torr. During these heat treatments, the $\mathrm{SiN}_{\mathrm{x}}$ coatings prevented reaction between the NiTi and the underlying substrate. Interfacial reactions in the $\mathrm{NiTi} / \mathrm{SiN}_{\mathrm{x}}$ system are significantly reduced compared to reactions in the $\mathrm{NiTi} / \mathrm{Si}$ and $\mathrm{NiTi} / \mathrm{SiO}_{2}$ systems under similar thermal conditions (Wu et al., 2004). On cooling from the heat treatment, the thermal mismatch between the NiTi films and the various substrates resulted in different levels of residual stress in NiTi films deposited to the same thickness but on different substrates.

The annealing conditions were chosen based on a study of the crystallization kinetics of amorphous NiTi films (Wang et al., 2008; Wang and Vlassak, 2006), with a goal of precisely tailoring the microstructure of the films. Several factors went into the selection of the annealing conditions: First, the same heat treatment had to crystallize the as-deposited NiTi films over the entire range of film thicknesses. This was an important consideration because the crystallization kinetics in NiTi thin films is thickness dependent and slows down significantly for very thin films (Wang et al., 2008). Second, the main point of interest in this study was the effect of film thickness on the martensitic transformation. Consequently the ideal film microstructure was one where the grains were much larger than the film thickness. Such a microstructure was achieved by choosing annealing conditions that minimized crystallite nucleation, while allowing a reasonable crystallite growth rate. Under the selected annealing conditions crystallite nucleation occurred homogeneously inside the amorphous films, resulting in films with a random crystallographic textur (Wang and Vlassak, 2006). 
The microstructure of the annealed films was examined using scanning electron microscopy (SEM, Zeiss Ultra55) and transmission electron microscopy (TEM, JEOL 2010 FEG, 200 kV). Cross-section TEM samples were prepared by mechanical tripod polishing and Ar ion beam milling. The phase composition of the films at room temperature was determined using X-ray diffraction with $\mathrm{Cu}-\mathrm{K}_{\alpha}$ radiation on a Bruker AXS diffractometers in a $\theta-2 \theta$ geometry. Scans were performed for $35^{\circ}<2 \theta<55^{\circ}$, because the (002), (111) and (012) reflections of the B19' martensite phase and the (110) reflection of the B2 austenite phase occur in this range.

The martensitic transformation behavior of the annealed NiTi films was investigated by measuring the film stress as a function of temperature using the substrate curvature technique. Prior to the stress measurements, the specimens were dipped in liquid nitrogen for 5 minutes and allowed to come back to room temperature to insure that the NiTi films were in the lowtemperature phase. The specimens were then thermally cycled between 15 and $120^{\circ} \mathrm{C}$ in a $\mathrm{He}$ atmosphere, while the curvature of the substrates was measured using a scanning laser beam (Witvrouw and Spaepen, 1993). Since the substrates were approximately three orders of magnitude thicker than the films, Stoney's equation could be used to calculate the film stress from the change in substrate curvature (Doerner and Nix, 1988). The biaxial moduli of the substrates used in Stoney's equation were 97.3, 80.0, 180.8 and 90.5 GPa for Corning glass, Pyrex glass, silicon and fused quartz respectively ${ }^{\dagger}$. The stress levels in the PECVD $\operatorname{SiN}_{\mathrm{x}}$ layers in both the as-deposited state and after heat treatment were determined from curvature measurements on a separate set of samples without NiTi films.

\footnotetext{
${ }^{\dagger}$ Corning glass, Pyrex glass and fused quartz are from CORNING Inc. Elastic moduli of these glass substrates were obtained from the vendor's technical datasheets.
} 


\section{Results and discussion}

\subsection{Microstructure characterization}

The microstructure of the crystalline NiTi films is illustrated in Fig. 1. Figure 1(a) shows a representative SEM micrograph of the surface of a $290 \mathrm{~nm}$ NiTi film. The surface relief caused by the martensite twins is quite evident in the micrograph. The average in-plane grain size of this film is approximately $15 \mu \mathrm{m}$, i.e., the aspect ratio of the pan-cake grains is approximately 50:1. Similar grain aspect ratios were also achieved for the other films. The large aspect ratio of the grains limits the interaction between adjacent grains and makes it possible to evaluate the effect

of film thickness independent of the grain size. For all practical purposes, the films can be regarded as single-crystal films of random overall orientation. Figure 1(b) depicts a typical crosssection TEM micrograph of the $290 \mathrm{~nm}$ NiTi film. The micrograph shows that there remains an amorphous NiTi layer of approximately $15 \mathrm{~nm}$ at both the top and bottom interfaces after the heat treatment. TEM examination of the other films showed that these amorphous layers were present in all annealed films and that their thickness is independent of the NiTi film thickness. These amorphous layers are the result of a small shift in NiTi composition at these locations, as verified by scanning transmission electron microscope (STEM) measurements (Wang et al., 2008; Wang and Vlassak, 2006) and are instrumental in obtaining the special grain structure required for the samples. The heat treatment at $450{ }^{\circ} \mathrm{C}$ for 20 minutes is not sufficient to crystallize the amorphous layers, but they can be crystallized at a higher temperature. The inset electron diffraction pattern taken from grain 2 shows 1/3(110) superlattice reflections indicating that the grain is in the R-phase rather than the B19' martensite phase. Instability of B19' martensite is typical in our cross-sectional TEM specimens and may be attributed to changes in the stress state and distribution in the thin-foil geometry of TEM specimens. Figure 2 shows the 
XRD spectra for the as-annealed NiTi films on Si substrates. Similar results were obtained for the films on the other substrates. The B19' martensite phase is dominant in all films except the $190 \mathrm{~nm}$ film, which has an austenite peak only. The scans further show that the martensitic films contain a small amount of residual austenite.

\subsection{Stress-temperature curves}

Figure 3 shows the residual stress in the as-deposited amorphous films at room temperature. The stress is tensile and increases slightly with increasing film thickness, indicative of a stress gradient through the thickness of the films. There is no statistically significant difference in the residual stress for films of a given thickness deposited on different types of substrates. This observation indicates that, thanks to the presence of the $\mathrm{SiN}_{\mathrm{x}}$ coating, the structure of the asdeposited films is independent of the substrate material.

The transformation behavior of the crystallized NiTi films was characterized by measuring the stress-temperature curves during thermal cycling. Figure 4 shows typical stress-temperature curves for the films deposited on silicon substrates. These curves have the typical sigmoidal shape associated with a reversible martensitic transformation. Upon cooling from elevated temperature, the NiTi films initially consist of austenite and any variation in stress is due to the thermal mismatch between the film stack and the substrate. On continued cooling, the austenite transforms to martensite and the stress relaxes abruptly to a lower level because of the selfaccommodating nature of the martensite twin structure. On subsequent heating, the reverse transformation to austenite leads to a complete recovery of the residual stress in the film. Figure 4 also shows that the stress in the austenite films varies with film thickness, but this is not necessarily a sign that there is a through-thickness stress gradient. The film stress in thermally 
cycled metallic films often increases with decreasing film thickness because the yield strength of a thin film increases with decreasing film thickness (Vinci and Vlassak, 1996).

To investigate the effect of film stress on the martensitic transformation in the NiTi quantitatively, the stress in the crystalline NiTi layer of the film stack needs to be determined first. It is evident from Fig. 1(b) that the film stacks consist of five distinct layers: two layers of PECVD $\mathrm{SiN}_{\mathrm{x}}$, two layers of amorphous NiTi and one layer of crystalline NiTi. Upon transformation, the stress in the crystalline NiTi layer relaxes but the amorphous NiTi layers remain at a high stress level. To obtain the stress in just the crystalline NiTi layer, the contributions of the other layers need to be accounted for. This is especially important for the thinner films where the thickness of the other layers is comparable to that of the crystalline NiTi layer. If the $\mathrm{SiN}_{\mathrm{x}}$ and the NiTi films (including both the amorphous and crystalline layers) have total thicknesses $h_{\mathrm{SiN}}$ and $h_{\mathrm{NiTi}}$, respectively, the average stress in the film stack, $\sigma_{f}$, is given by the thickness-weighted average of the stresses in these layers

$\sigma_{f}=\sigma_{S i N} \frac{h_{S i N}}{h_{S i N}+h_{N i T i}}+\sigma_{N i T i} \frac{h_{N i T i}}{h_{S i N}+h_{N i T i}}$,

where $\sigma_{\mathrm{SiN}}$ and $\sigma_{\mathrm{NiTi}}$ are the stresses in the respective layers. The stress in the $\mathrm{SiN}_{\mathrm{x}}$ films on the Si substrate was measured to be $348 \pm 25 \mathrm{MPa}$ and did not change appreciably over the temperature range of the curvature measurements. Given the stress in the $\mathrm{SiN}_{\mathrm{x}}$, the stress in the NiTi film is readily calculated using Eq. (1). After subtracting the contribution of the $\operatorname{SiN}_{\mathrm{x}}$ coatings, the stress in the NiTi martensite (i.e., at room temperature) is still thickness dependent, increasing slightly with decreasing film thickness. This observation is somewhat surprising given the large recoverable strain associated with the martensitic transformation. Below we demonstrate that this thickness dependence does not arise because the transformation strain is 
exhausted for the thinner films and thus unable to fully relax the stress in the films. Instead it is caused by the presence of the thin layers of amorphous NiTi. If we denote the amorphous and crystalline NiTi layers as layers $a$ and $c$ with thicknesses $h_{a}$ and $h_{\mathrm{c}}$, respectively, the stress in the NiTi film, $\sigma_{\mathrm{NiTi}}$, is given by

$$
\sigma_{N i T i}=\sigma_{a} \frac{h_{a}}{h_{N i T i}}+\sigma_{c} \frac{h_{c}}{h_{N i T i}},
$$

where $\sigma_{\mathrm{a}}$ and $\sigma_{\mathrm{c}}$ are the stresses in the respective layers. Rearranging Eq. (2) yields

$$
\sigma_{N i T i}=\sigma_{c}+\left(\sigma_{a}-\sigma_{c}\right) \frac{h_{a}}{h_{N i T i}}
$$

According to Eq. (3), the stress in the crystalline section of the NiTi layer, $\sigma_{\mathrm{c}}$, is given by the intercept on the stress axis of a graph of $\sigma_{\mathrm{NiTi}} \mathrm{vs} .1 / h_{\mathrm{NiTi}}$. The stress in the amorphous layers can be calculated from the slope. Figure 5 shows a graph of the stress in the NiTi layer at room temperature as a function of the reciprocal NiTi film thickness. Results for all NiTi films on silicon substrates are shown with the exception of the $190 \mathrm{~nm}$ film, which did not completely transform to martensite at room temperature. The stress in the martensite increases linearly with increasing reciprocal film thickness at a rate of $8.72 \mathrm{MPa} \cdot \mu \mathrm{m}$. Considering that $h_{a}=30 \mathrm{~nm}$, we find that the stress in the amorphous NiTi has a value of $320 \pm 42 \mathrm{MPa}$, while the stress in the martensitic NiTi is $28 \pm 2 \mathrm{MPa}$. Similar analyses were conducted for the films on the Pyrex glass and fused quartz substrates and the results are summarized in Table 2. Evidently the stress in the martensite is independent of the substrate material, while the stress in the amorphous layer increases with increasing thermal mismatch between film and substrate. 


\subsection{Stress-related effects on transformation behavior}

Figure 6(a) shows the stress in the crystallized NiTi films on the Si substrates as a function of temperature after correcting for the stress in the $\mathrm{SiN}_{\mathrm{x}}$ and the amorphous NiTi layers. Similar results were obtained for the films on the Pyrex and fused quartz substrates and are shown in Figs. 6(b) and (c). It is evident that the hysteresis loops caused by the martensitic forward and reverse transformations shift to lower temperatures as the film thickness decreases. A direct comparison of the martensite transformation temperatures is misleading, however, because the films are at different residual stress levels when the transformation starts. The effect of stress on the transformation temperature is well documented for bulk materials (Otsuka and Wayman, 1999). For thin films, the effect of stress can be evaluated as follows. Figure 7 shows the stresstemperature curves for the $910 \mathrm{~nm}$ NiTi films deposited on three different substrates. The results obtained for the Corning glass substrate are not included here for reasons that will be discussed later. Because of the different thermal mismatches between film and substrate material, the stress in the austenite film is different for each type of substrate. Along with the different stress, there is also a shift in transformation temperature. Although the stress in the austenite film is different when the transformation starts, the transformation follows the same $\sigma(T)$ curve during the forward and reverse transformation. The key characteristic of the stress-temperature curve during the transformation is its slope $\mathrm{d} \sigma / \mathrm{d} T$, which is independent of the stress in the austenite. The values of the slopes measured in this study are plotted as a function of film thickness in Fig. 8. The slope rises from approximately $23 \mathrm{MPa} / \mathrm{K}$ for the $910 \mathrm{~nm}$ films to a little over $30 \mathrm{MPa} / \mathrm{K}$ for the thinnest films. Similar values were reported previously for sputter deposited NiTi films on substrates (Grummon and Zhang, 2001; Liu and Huang, 2004). Roytburd et al. (Roytburd et al., 1998) derived a modified Clapeyron-Clausius relationship to describe the equilibrium 
transformation of austenite to martensite in a single crystal on a substrate and calculated a slope of approximately $7 \mathrm{MPa} / \mathrm{K}$ for a single-crystal NiTi film with a (110) orientation. The basic assumptions underlying this thermodynamic model are that the martensite plates are very thin compared to the film thickness and that the plates are finely distributed throughout the film. It was shown by Shu and Bhattacharya (Shu and Bhattacharya, 1998) that the recoverable strain for a film with a (110) texture should be the same as for a film with a random texture, so that the value of the equilibrium slope should be the same as well. By contrast much larger values of the slope are observed in this study. It has also been suggested that the slope is the result of a stress gradient through the thickness of the austenite film and that the temperature range over which the transformation occurs is a measure for the stress gradient in the film (Liu and Huang, 2004). The stress gradient model cannot explain, however, why the slopes in this study are significantly larger than the slope predicted by the thermodynamic model. If anything, a stress gradient would result in an even shallower slope. We will show later that the austenite to martensite transformation in a thin single-crystal SMA film on a substrate occurs at a fixed temperature that depends on the stress in the film, at least as long as the martensite plates form through the thickness of the film and the austenite is perfectly constrained by the substrate. The finite slope observed in the experiments can then be attributed to the relaxation of the stress in austenite adjacent to martensite plates, as well as to the grain-to-grain variation of the stress in the austenite that arises because of the elastic anisotropy of the austenite grains - larger thermal stresses develop in grains with larger in-plane moduli.

The results in Fig. 7 show that the stress in the martensite film is very small and independent of the stress in the austenite film. Furthermore, there is a temperature range over which the stress in the martensite is nearly constant, i.e., no thermal stress develops. Since most of the austenite 
has transformed to martensite in this temperature range (e.g., see XRD spectra in Fig. 2), this region of stress invariance can be attributed to a simple rearrangement of the martensite variants on further cooling. Both of these observations are clear indications that the transformation strain is not exhausted by the stress drop as noted in the previous section (Roytburd and Slutsker, 2002).

When the thermal stress in the austenite is less than $\sim 300 \mathrm{MPa}$, the transformation path from austenite to martensite is changed. Figure 9 shows the stress-temperature curve in a $910 \mathrm{~nm} \mathrm{NiTi}$ film on a $\mathrm{SiN}_{\mathrm{x}}$-coated Corning glass substrate. The thermal mismatch between Corning glass and $\mathrm{NiTi}$ is small and as a result the residual stress in the austenite is quite low after annealing. As shown in Fig. 9, the stress-temperature behavior of this film is qualitatively different from the behavior for the other substrates. Rather than one stress relaxation step, there are two distinct stress drops on cooling. XRD results (not shown) indicate that the first stress drop is due to formation of the R-phase, while the second drop is caused by formation of B19' martensite. The presence of the R-phase is further confirmed by the small temperature hysteresis between the forward and reverse transformations that occurs if the film is reheated before the B19' phase forms (open symbols in the figure). This observation indicates that the film stress affects the transformation sequence and product, in agreement with reports in the literature that bulk NiTi material undergoes a two-step transformation, $\mathrm{B}_{2} \rightarrow \mathrm{R}$-phase $\rightarrow$ B19', if the applied stress is low (Craciunescu et al., 2003; Stachowiak and McCormick, 1988). The reverse transformation, however, is a one-step transformation to austenite.

\subsection{Thickness-dependent transformation behavior}

As illustrated in Fig. 6 and Fig. 7, the martensitic transformation temperature shifts to lower temperature as the film thickness or the film stress decreases. The austenite-to-martensite transformation start temperature, $M_{s}$, and the film stress at which the transformation starts, $\sigma_{A}$, 
can be determined for each film as the point of first deviation in the cooling path of stresstemperature curve. Figure 10 shows the transformation temperature as a function of film stress and thickness. The figure demonstrates that the $M_{s}$ temperature shifts to lower values as the film thickness decreases, while an increasing film stress has the opposite effect.

The effect of film thickness on the martensite transformation temperature is illustrated further in Fig. 11, which shows the $M_{s}$ temperature at a reference stress of $500 \mathrm{MPa}$ as determined from curve fits to the data in Fig. 10. The precise equation for the curve fit does not have a large effect on the result and will be discussed later. It is evident that the martensitic transformation shifts to lower temperatures as the film thickness decreases. The effect is small for thick films, but becomes quite pronounced for films thinner than $400 \mathrm{~nm}$. The films in this study have a small composition shift in the amorphous layers at the $\mathrm{NiTi} / \mathrm{SiN}_{\mathrm{x}}$ interfaces (Wang and Vlassak, 2006). The crystalline layer, however, has the same near-equiatomic composition as the as-deposited amorphous film. The depression of the transformation temperature cannot be attributed to a shift in composition caused by a reaction with the $\mathrm{SiN}_{\mathrm{x}}$ layers. The transformation temperature of the $290 \mathrm{~nm}$ film is approximately $25^{\circ} \mathrm{C}$ lower than that of the $910 \mathrm{~nm}$ film. If this change were due to a shift in composition, the entire film would have to be approximately 0.25 at.\% richer in $\mathrm{Ni}$, based on the composition dependence of the transformation temperature of bulk NiTi (Tang, 1997). If the $190 \mathrm{~nm}$ film is considered, the composition shift would have to be nearly 1 at.\%. This is impossible for the annealing conditions in this study given the slow diffusion in amorphous NiTi (Janicki and Grundy, 1986). We conclude that the observed decrease in transformation temperature with film thickness is an intrinsic size effect.

It was reported in a TEM study by Waitz and coworkers (Waitz and Karnthaler, 2004; Waitz et al., 2004) that a two-step transformation, B2 $\rightarrow$ R-phase $\rightarrow$ B19', occurs in both isolated NiTi 
nano-crystals embedded in an amorphous matrix and in nano-crystals in nanocrystalline alloys when the crystallite size decreases below a critical value. This transformation path leads to the formation of (001) B19' compound twins in the martensite. We have not seen any evidence for such a two-step transformation with decreasing film thickness, although a two-step transformation does occur for films with low values of residual stress. We also have not observed any (001) B19' compound twins in our films. It is possible that much smaller film thicknesses are required for the two-step transformation to occur or compound twins to form.

\subsection{Micromechanics of constrained transformation behavior}

We have investigated the transformation behavior of NiTi films constrained by a substrate. The effect of film thickness on the transformation temperature suggests that the substrate constraint has a significant effect on the transformation. Here we develop a simple micromechanics model to explain the observed effect.

As illustrated schematically in Fig. 12, a poly-domain martensite plate forms through the thickness of an austenite grain. Following our experimental results, we assume that the martensite variants in this plate are those that relax the stress in the plate to zero. The martensite plate also reduces the stress state in the adjacent austenite. If the spacing between the martensite plates is large compared to the film thickness, the stress in the adjacent austenite is only partially relaxed because of the constraint imposed by the substrate. The extent of relaxation depends on the precise geometry and the elastic mismatch between film and substrate. Here we only consider the limiting case where the stress relaxation in the austenite is negligible, i.e., the stress profile approaches a step function across the austenite/martensite interface. The free energy for such an austenite-martensite mixture constrained by a substrate is given by: 
$f(\alpha)=(1-\alpha) f_{A}^{0}+\alpha f_{M}^{0}+e(\alpha)+W_{s}(\alpha)$,

where $\alpha$ is the martensite volume fraction. The quantities $f_{\mathrm{A}}{ }^{0}$ and $f_{\mathrm{M}}{ }^{0}$ are the free energies per unit volume of the unstressed austenite and martensite. The term $e(\alpha)$ is the internal energy of the self-accommodated martensite, which consists of the energy associated with the various interfaces in the film and the elastic energy of the short-range internal stresses. This term can be written as $e_{0} \alpha$ where $e_{0}$ is the corresponding energy density (Roytburd et al., 1998). The term $W_{s}(\alpha)$ is elastic strain energy due to the residual stress in the austenite. Assuming isotropic elasticity and no stress relaxation in the austenite, Eq. (4) can be rewritten as

$f(\alpha)=f_{A}^{0}+\alpha\left(f_{M}^{0}-f_{A}^{0}+e_{0}\right)+(1-\alpha) \frac{\sigma^{2}(1-v)}{E}$,

where $E$ and $v$ are Young's modulus and Poisson's ratio of the film. It is evident from Eq. (5) that the transformation from austenite to martensite will occur if

$f_{M}^{0}-f_{A}^{0}+e_{0}=\frac{\sigma^{2}(1-v)}{E}$,

i.e., the transformation starts and finishes at a single temperature, which depends on the austenite film stress. The resulting stress-temperature curve has an infinite slope at the transformation temperature. The infinite slope is the result of the rather simplistic assumption that no stress relaxation occurs in the austenite adjacent to the martensite plates. In actual practice, some relaxation does occur and the slope will be finite. In addition to stress relaxation, any stress heterogeneity in the film, either grain to grain or across the film thickness, will further act to reduce the slope. It should be emphasized that this simple model is valid only if the martensite plates grow through the thickness of the film with a width that is comparable to or greater than 
the film thickness. The image in Fig. 1(a) suggests that this is a reasonable assumption for the films in this study. If the martensite plates are very thin and finely distributed throughout the film, the thermodynamic analysis by Roytburd and coworkers (Roytburd et al., 1998) should provide a better description. The model is also consistent with the observation that the stress-temperature slope increases when the grain size and hence the martensite plate width increases (Roytburd et al., 1998).

Using Turnbull's approximation, $f_{A}^{0}-f_{M}^{0} \approx L\left(T_{0}-T\right) / T_{0}$, for the free energy in Eq. (6) shows that the transformation temperature increases with the square of the residual stress in the film:

$M_{s} \approx T_{0}+\frac{T_{0}}{L}\left(\frac{\sigma^{2}(1-v)}{E}-e_{0}\right)$

where $T_{0}$ is the stress-free equilibrium temperature between austenite and martensite and $L$ is the latent heat of transformation. The data in Fig. 10 were fitted using this equation. The equation further indicates that the transformation temperature decreases with increasing internal energy density $e_{\mathrm{o}}$, i.e., with decreasing film thickness as we will demonstrate below.

When the austenite transforms to martensite, the large transformation strains are accommodated through the formation of a poly-domain microstructure that contains many martensite variants or twins and that minimizes the overall incompatibility between the martensite and austenite. The condition for the onset of the transformation can be written as

$f_{A}^{0}-f_{M}^{0}=U_{B}$, 
where $U_{B}$ represents the energy barrier to transformation, which comprises the energy per unit volume associated with the various interfaces, the elastic energy of the internal stresses, and an energy dissipation term we refer to as a friction term:

$U_{B}=\Gamma_{P B}+\Gamma_{P A}+\Gamma_{S}+W_{P S}-W_{A u}+F_{C}$.

The components of $U_{B}$ are illustrated schematically in Fig. 13, which shows twinned martensite plates in an austenite film. $\Gamma_{P B}$ is the interfacial energy between martensite plates; $\Gamma_{P A}$ is the energy of the martensite/austenite interfaces; $\Gamma_{S}$ is the change in interfacial energy between film and substrate or capping layer as a result of the transformation. $W_{P S}$ is the strain energy caused by the interaction between the martensite plates and the substrate or the capping layer. $F_{c}$ is the friction term that represents the work dissipated per unit volume of martensite as a result of inelastic processes. This term scales with the degree of incompatibility between the austenite and the martensite and is in part responsible for the transformation hysteresis between heating and cooling (James and Zhang, 2005; Zarnetta et al., 2010). The term $W_{\mathrm{Au}}$ represents the strain energy associated with the residual stresses in the austenite. Because of its self-accommodating nature, formation of the martensite phase results in a local reduction of the residual stresses in the coating and hence in a reduction of the strain energy. Consequently, the presence of residual stresses in the austenite lowers the transformation barrier. The various energy terms in Eq. (9) scale differently with film thickness and martensite plate width. Writing these dependencies explicitly, we obtain

$U_{B}=\frac{\gamma_{P B}+\gamma_{P A}}{d}+\frac{\gamma_{S}}{h}+w_{P S} \frac{d}{h}-W_{A u}+F_{C}$,

where $d$ represents the martensite plate width, $h$ the film thickness, and where $\gamma_{P B}, \gamma_{P A}, \gamma_{S}$, and $w_{P S}$ are defined through a term-by-term comparison of Eqs. (9) and (10). The friction term 
depends on the incompatibility between the martensite and austenite crystal structures, and its scaling with microstructure is not clear. However, given that the transformation hysteresis does not change much with film thickness, we take this term to first order independent of any microstructural length scales. Minimizing the energy barrier with respect to $d$ shows that the plate width scales with the square root of the film thickness. Equation (10) can then be rewritten as

$U_{B}=2 \sqrt{\frac{\left(\gamma_{P B}+\gamma_{P A}\right) w_{P S}}{h}}+\frac{\gamma_{S}}{h}-W_{A u}+F_{C}$.

According to this expression, the barrier to transformation increases with decreasing film thickness. Using the Turnbull approximation, $f_{A}^{0}-f_{M}^{0} \approx L\left(T_{0}-T\right) / T_{0}$, it is possible to estimate the transformation start temperature from Eqs. (8) and (11). Figure 14 shows the transformation start temperature as a function of film thickness based on material parameters for NiTi taken from literature (Waitz et al., 2007) as shown in Table 3. The experimental transformation temperatures obtained in this study are also shown. The theory clearly predicts the correct trend, but the experimental data drop off faster. The lack of quantitative agreement is of course not entirely unexpected given the complexity of martensitic transformation process and the uncertainty in the energy terms in theory.

\section{Conclusions}

The following conclusions can be drawn based on our experimental observations:

1. The grain size of sputtered NiTi thin films can be tailored by choosing an appropriate heat treatment to crystallize the amorphous as-deposited coatings. Very large grain 
aspect ratios can be obtained for a wide range of coating thicknesses. These large aspect ratios ensure that the martensitic transformation is not affected by the grain size of the coatings.

2. By measuring the residual stress in $\mathrm{SiN}_{\mathrm{x}}$-capped $\mathrm{NiTi}$ coatings as a function of temperature using the substrate curvature technique, it is possible to evaluate the effects of film stress and film thickness on the martensitic transformation temperature even for very thin films. The martensite transformation temperature decreases rapidly with increasing film stress and decreasing film thickness.

3. The stress drop associated with the transformation occurs over a narrow temperature range, much narrower in fact than predicted by existing models. This observation is attributed to the constraint imposed on the NiTi coatings by the underlying substrate when the martensite plate size is on the order of the film thickness.

4. The decrease in transformation temperature with decreasing film thickness is not caused by a change in composition and must therefore be attributed to microstructural and geometric factors. A simple model shows that the energy barrier for the martensitic transformation indeed increases with decreasing film thickness, causing a commensurate decrease in transformation temperature.

5. The level of film stress can change the transformation sequence and product. If the residual stress in the NiTi films is low, a two-step transformation of $\mathrm{B}_{2} \rightarrow$ R-phase $\rightarrow \mathrm{B} 19^{\prime}$ occurs instead of the direct $\mathrm{B}_{2} \rightarrow \mathrm{B} 19^{\prime}$ transformation for films with larger residual stress. 


\section{Acknowledgements}

This work was funded by the National Science Foundation (DMR-0133559, DMR-

0906892). One of the authors (X.W.) would like to thank the National Natural Science Foundation of China (Grant No. 11002150) for partial support. 


\section{TABLES}

TABLE 1. Deposition conditions of PECVD SiNx film

\begin{tabular}{|c|c|}
\hline Base pressure (Torr) & $1 \times 10^{-7}$ \\
\hline Working pressure (mTorr) & 10 \\
\hline $\mathrm{Ar}(\mathrm{sccm})$ & 20 \\
\hline $\mathrm{N}_{2}(\mathrm{sccm})$ & 5.8 \\
\hline $\mathrm{SiH}_{4}(\mathrm{sccm})$ & 40 \\
\hline Microwave $(\mathrm{W})$ & 265 \\
\hline Deposition rate $(\AA / \mathrm{s})$ & 1.1 \\
\hline
\end{tabular}

TABLE 2. Results of stress determination in NiTi films

\begin{tabular}{|c|c|c|c|}
\hline Substrate & $\begin{array}{c}\text { Stress in } \mathrm{SiN}_{\mathrm{x}}, \sigma_{\mathrm{SiN}} \\
(\mathrm{MPa})\end{array}$ & $\begin{array}{c}\text { Stress in martensite NiTi, } \sigma_{\mathrm{c}} \\
(\mathrm{MPa})\end{array}$ & $\begin{array}{c}\text { Stress in amorphous NiTi, } \sigma_{\mathrm{a}} \\
(\mathrm{MPa})\end{array}$ \\
\hline Pyrex & $285 \pm 31$ & $32 \pm 3$ & $263 \pm 43$ \\
\hline Silicon & $348 \pm 25$ & $28 \pm 2$ & $320 \pm 42$ \\
\hline Fused quartz & $530 \pm 47$ & $22 \pm 8$ & $501 \pm 140$ \\
\hline
\end{tabular}

TABLE 3. Material parameters for NiTi (Waitz et al., 2007)

\begin{tabular}{|c|c|}
\hline Elastic constants of NiTi & $E=58 \mathrm{GPa}, v=0.42$ \\
\hline Interfacial energy & $\gamma_{P B}=0.01 \mathrm{~J} / \mathrm{m}^{2}, \gamma_{P A}=0.1 \mathrm{~J} / \mathrm{m}^{2}, \gamma_{S}=0.1 \mathrm{~J} / \mathrm{m}^{2}$ \\
\hline Strain energy & $w_{P S}=E \varepsilon_{T}^{2} / 2(1+v)=2 \times 10^{8} \mathrm{~J} / \mathrm{m}^{3}\left(\varepsilon_{T}=0.1\right)$, \\
& $W_{A u}=\sigma_{\mathrm{f}}^{2}(1-v) / E=2.5 \times 10^{6} \mathrm{~J} / \mathrm{m}^{3}\left(\sigma_{\mathrm{f}}=500 \mathrm{MPa}\right)$ \\
\hline Work of friction & $F_{c}=5.8 \times 10^{6} \mathrm{~J} / \mathrm{m}^{3}$ \\
\hline Latent heat & $L=1.85 \times 10^{8} \mathrm{~J} / \mathrm{m}^{3}$ \\
\hline Temperature of chemical equilibrium & $T_{0}=370 \mathrm{~K}$ \\
\hline
\end{tabular}




\section{LIST OF FIGURE CAPTIONS}

Figure 1. Microstructure of a $290 \mathrm{~nm}$ NiTi film after the heat treatment. (a) SEM micrograph of the film surface showing the surface relief caused by martensitic transformation. (b) Cross-section TEM micrograph showing multiple layer structure of NiTi film. The inset electron diffraction pattern taken from grain 2 shows 1/3(110) superlattice reflections indicating the grain is in the R-phase.

Figure 2. XRD spectra for as-annealed NiTi films on Si substrate with different thicknesses.

Figure 3. Residual stress in as-deposited amorphous thin films on different substrate materials.

Figure 4. Stress-temperature curves for the NiTi film stacks on Si substrates. The contribution of the $\mathrm{SiN}_{\mathrm{x}}$ coatings has not been subtracted.

Figure 5. Film stacks on silicon substrates: Residual stress at room temperature as a function of reciprocal film thickness after subtracting the contributions of the $\mathrm{SiN}_{\mathrm{x}}$ coatings.

Figure 6. Stress in the crystalline layers of the NiTi films as a function of temperature: (a) Films on silicon substrates; (b) Films on Pyrex substrate; (c) Films on fused quartz substrate.

Figure 7. Film stress in $910 \mathrm{~nm}$ film on different substrates as a function of temperature.

Figure 8 . The slope $\mathrm{d} \sigma / \mathrm{d} T$ of the stress-temperature curve along the transformation path upon cooling.

Figure 9. Stress-temperature curve for a NiTi film on a Corning glass substrate. The inset shows the thermal history in the measurement; open symbols in the inset correspond to open symbols in the stress-temperature curve. 
Figure 10. Transformation temperature as a function of film stress and film thickness. Curve fits are based on Eq. (7) in the text using the same coefficient B for the stress term for all data sets.

Figure 11. $M_{s}$ transformation temperature at a film stress of $500 \mathrm{MPa}$ as a function of film thickness. Transformation temperatures were calculated at the reference stress using the curve fits in Fig. 10.

Figure 12. Stress profile inside the two-phase film.

Figure 13. Energy terms associated with transformation.

Figure 14. Comparison of the model with experiment for transformation temperature. 


\section{References}

Craciunescu, C., Li, H., Wuttig, M., 2003. Thermoelastic stress-induced thin film martensites. Scripta Materialia 48, 65-70.

Doerner, M.F., Nix, W.D., 1988. Stresses and deformation processes in thin films and substrates. CRC Critical Reviews in Solid State and Materials Sciences 14, 225-268.

Fu, Y.Q., Du, H.J., Huang, W.M., Zhang, S., Hu, M., 2004. TiNi-based thin films in MEMS applications: a review. Sensors and Actuators A: Physical 112, 395-408.

Fu, Y.Q., Zhang, S., Wu, M.J., Huang, W.M., Du, H.J., Luo, J.K., Flewitt, A.J., Milne, W.I., 2006. On the lower thickness boundary of sputtered TiNi films for shape memory application. Thin Solid Films 515, 80-86.

Grummon, D.S., Zhang, J.P., 2001. Stress in sputtered films of near-equiatomic TiNiX on (100)

Si: Intrinsic and extrinsic stresses and their modification by thermally activated mechanisms. Physica Status Solidi a-Applied Research 186, 17-39.

Ishida, A., Martynov, V., 2002. Sputter-deposited shape-memory alloy thin films: Properties and applications. MRS Bulletin 27, 111-114.

Ishida, A., Sate, M., Takei, A., Miyazaki, S., 1995. Effect of heat treatment on shape memory behavior of Ti-rich Ti-Ni thin films. Materials Transactions 36, 1349-1355.

James, R.D., Zhang, Z., 2005. A way to search for multiferroic materials with "unlikely" combinations of physical properties, in: Planes, A., Mañosa, L., Saxena, A. (Eds.), Magnetism and Structure in Functional Materials. Springer, pp. 159-175.

Janicki, A.J., Grundy, P.J., 1986. A transmission electron-microscope study of the effects of irradiation on the crystallization of a Ni60Ti40 amorphous alloy. Journal of Physics D-Applied Physics 19, L49-\&. 
König, D., Buenconsejo, P.J.S., Grochla, D., Hamann, S., Pfetzing-Micklich, J., Ludwig, A., 2012. Thickness-dependence of the B2-B19 martensitic transformation in nanoscale shape memory alloy thin films: Zero-hysteresis in 75nm thick Ti51Ni38Cu11 thin films. Acta Materialia 60, 306-313.

König, D., Zarnetta, R., Sayan, A., Brunken, H., Ludwig, A., 2011. Phase transformation, structural and functional fatigue properties of Ti-Ni-Hf shape memory thin films. Acta Materialia $59,3267-3275$.

Liu, Y., Huang, X., 2004. Substrate-induced stress and transformation characteristics of a deposited Ti-Ni-Cu thin film. Philosophical Magazine 84, 1919-1936.

McCluskey, P.J., Zhao, C.W., Kfir, O., Vlassak, J.J., 2011. Precipitation and thermal fatigue in Ni-Ti-Zr shape memory alloy thin films by combinatorial nanocalorimetry. Acta Materialia 59, 5116-5124.

Miyazaki, S., Ishida, A., 1994. Shape memory characteristics of sputter deposited TiNi thin films. Materials Transactions 35, 14-19.

Otsuka, K., Ren, X., 2005. Physical metallurgy of Ti-Ni-based shape memory alloys. Progress in Materials Science 50, 511-678.

Otsuka, K., Wayman, C.M., 1999. Shape memory materials, 1st ed. Cambridge University Press, Cambridge.

Roytburd, A.L., 1998a. Thermodynamics of polydomain heterostructures. I. effect of macrostress. Journal of Applied Physics 83, 228-238.

Roytburd, A.L., 1998b. Thermodynamics of polydomain heterostructures. II. effect of microstress. Journal of Applied Physics 83, 239-245. 
Roytburd, A.L., Kim, T.S., Su, Q.M., Slutsker, J., Wuttig, M., 1998. Martensitic transformation in constrained films. Acta Materialia 46, 5095-5107.

Roytburd, A.L., Slutsker, J., 2001. Deformation of adaptive materials. Part III: Deformationof crystals with polytwin product phases. Journal of the Mechanics and Physics of Solids 49, 19751822.

Roytburd, A.L., Slutsker, J., 2002. Theory of multilayer SMA actuators. Materials Transactions 43, 1023-1029.

Shih, C.L., Lai, B.K., Kahn, H., Phillips, S.M., Heuer, A.H., 2001. A robust Co-sputtering fabrication procedure for TiNi shape memory alloys for MEMS. Journal of Microelectromechanical Systems 10, 69-79.

Shu, Y.C., Bhattacharya, K., 1998. The influence of texture on the shape-memory effect in polycrystals. Acta Materialia 46, 5457-5473.

Stachowiak, G.B., McCormick, P.G., 1988. Shape memory behavior associated with the R and martensitic transformations in a NiTi alloy. Acta Metallurgica 36, 291-297.

Tang, W.J., 1997. Thermodynamic study of the low-temperature phase B19' and the martensitic transformation in near-equiatomic Ti-Ni shape memory alloys. Metallurgical and Materials Transactions a-Physical Metallurgy and Materials Science 28, 537-544.

Tomozawa, M., Kim, H.Y., Miyazaki, S., 2009. Shape memory behavior, and internal structure of Ti-Ni-Cu shape memory alloy thin films and their application for microactuators. Acta Materialia 57, 441-452.

Vinci, R.P., Vlassak, J.J., 1996. Mechanical behavior of thin films. Annual Review of Materials Science 26, 431-462. 
Waitz, T., Antretter, T., Fischer, F.D., Simha, N.K., Karnthaler, H.P., 2007. Size effects on the martensitic phase transformation of NiTi nanograins. Journal of the Mechanics and Physics of Solids 55, 419-444.

Waitz, T., Karnthaler, H.P., 2004. Martensitic transformation of NiTi nanocrystals embedded in an amorphous matrix. Acta Materialia 52, 5461-5469.

Waitz, T., Kazykhanov, V., Karnthaler, H.P., 2004. Martensitic phase transformations in nanocrystalline NiTi studied by TEM. Acta Materialia 52, 137-147.

Wang, X., Rein, M., Vlassak, J.J., 2008. Crystallization kinetics of amorphous equiatomic NiTi thin films: Effect of film thickness. Journal of Applied Physics 103.

Wang, X., Vlassak, J.J., 2006. Crystallization kinetics of amorphous NiTi shape memory alloy thin films. Scripta Materialia 54, 925-930.

Winzek, B., Schmitz, S., Rumpf, H., Sterzl, T., Hassdorf, R., Thienhaus, S., Feydt, J., Moske, M., Quandt, E., 2004. Recent developments in shape memory thin film technology. Materials Science and Engineering: A 378, 40-46.

Witvrouw, A., Spaepen, F., 1993. Determination of the plane-stress elastic-constants of thinfilms from substrate curvature measurements: applications to amorphous metals. Journal of Applied Physics 73, 7344-7350.

Wolf, R.H., Heuer, A.H., 1995. TiNi (shape memory) films on silicon for MEMS applications. Journal of Microelectromechanical Systems 4, 206-212.

Wu, S.K., Su, J.J., Wang, J.Y., 2004. Interfacial reactions of rf-sputtered TiNi thin films on (100) silicon with a SiN diffusion barrier. Philosophical Magazine 84, 1209-1218.

Zarnetta, R., Takahashi, R., Young, M.L., Savan, A., Furuya, Y., Thienhaus, S., Maaß, B., Rahim, M., Frenzel, J., Brunken, H., Chu, Y.S., Srivastava, V., James, R.D., Takeuchi, I., 
Eggeler, G., Ludwig, A., 2010. Identification of quaternary shape memory alloys with near-zero thermal hysteresis and unprecedented functional stability. Advanced Functional Materials 20, 1917-1923. 


\section{FIGURES}

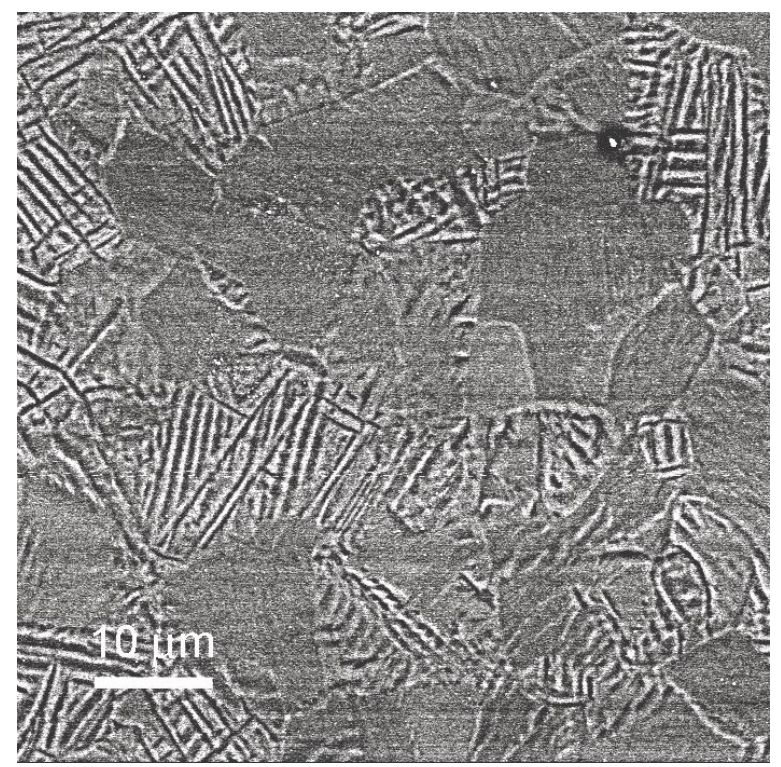

(a)

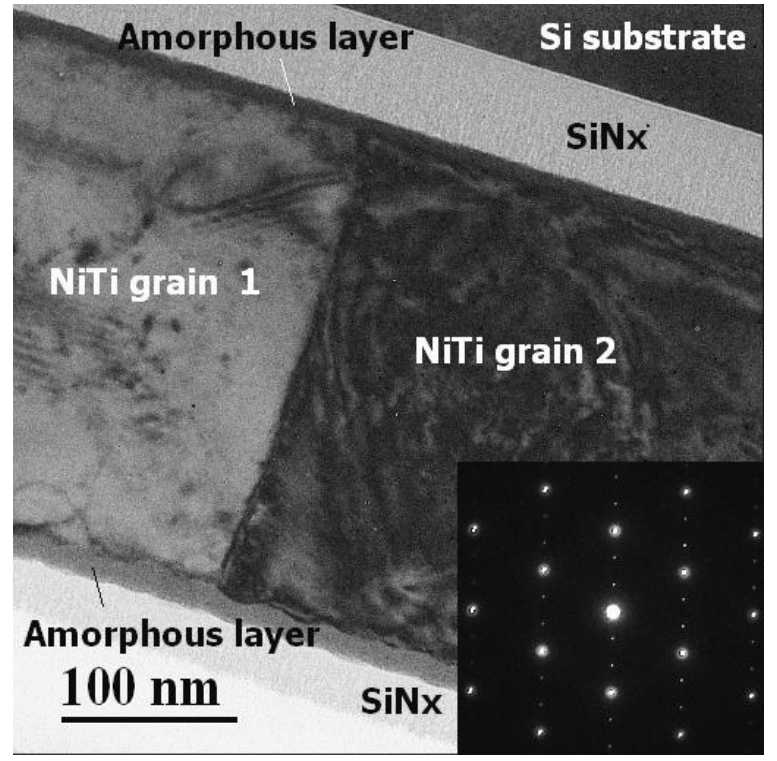

(b)

Fig. 1. Microstructure of a $290 \mathrm{~nm}$ NiTi film after the heat treatment. (a) SEM micrograph of the film surface showing the surface relief caused by martensitic transformation. (b) Cross-section TEM micrograph showing multiple layer structure of NiTi film. The inset electron diffraction pattern taken from grain 2 shows 1/3(110) superlattice reflections indicating the grain is in the Rphase. 


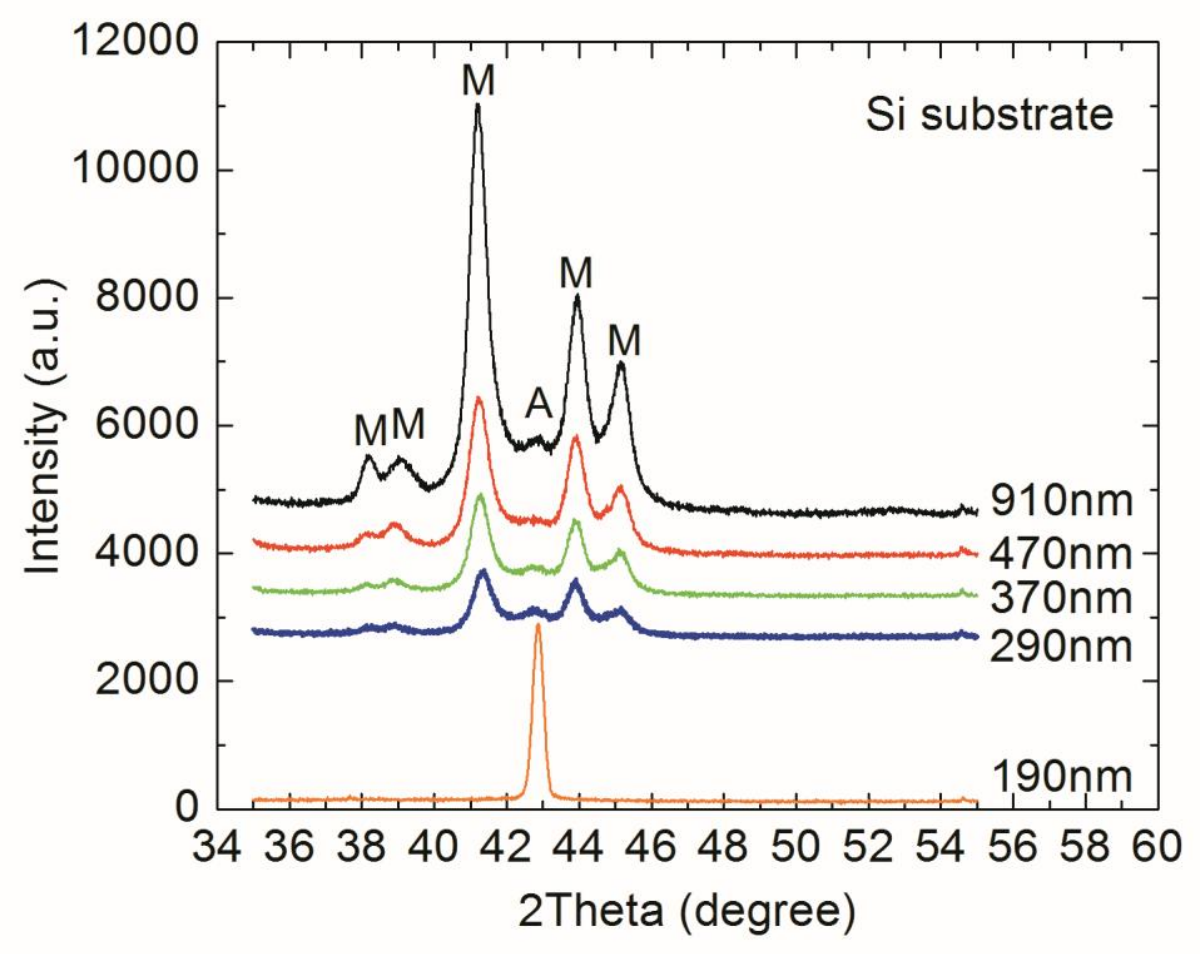

Fig. 2. XRD spectra for as-annealed NiTi films on Si substrate with different thicknesses. 


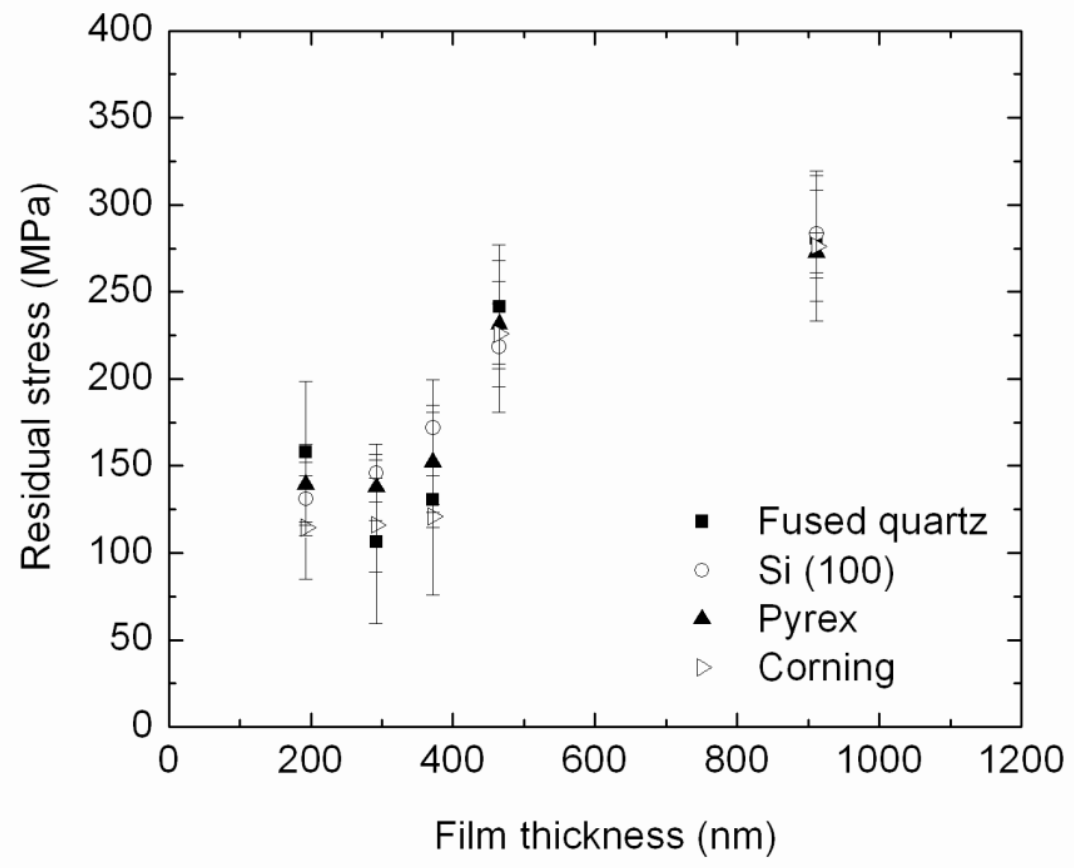

Fig. 3. Residual stress in as-deposited amorphous thin films on different substrate materials. 


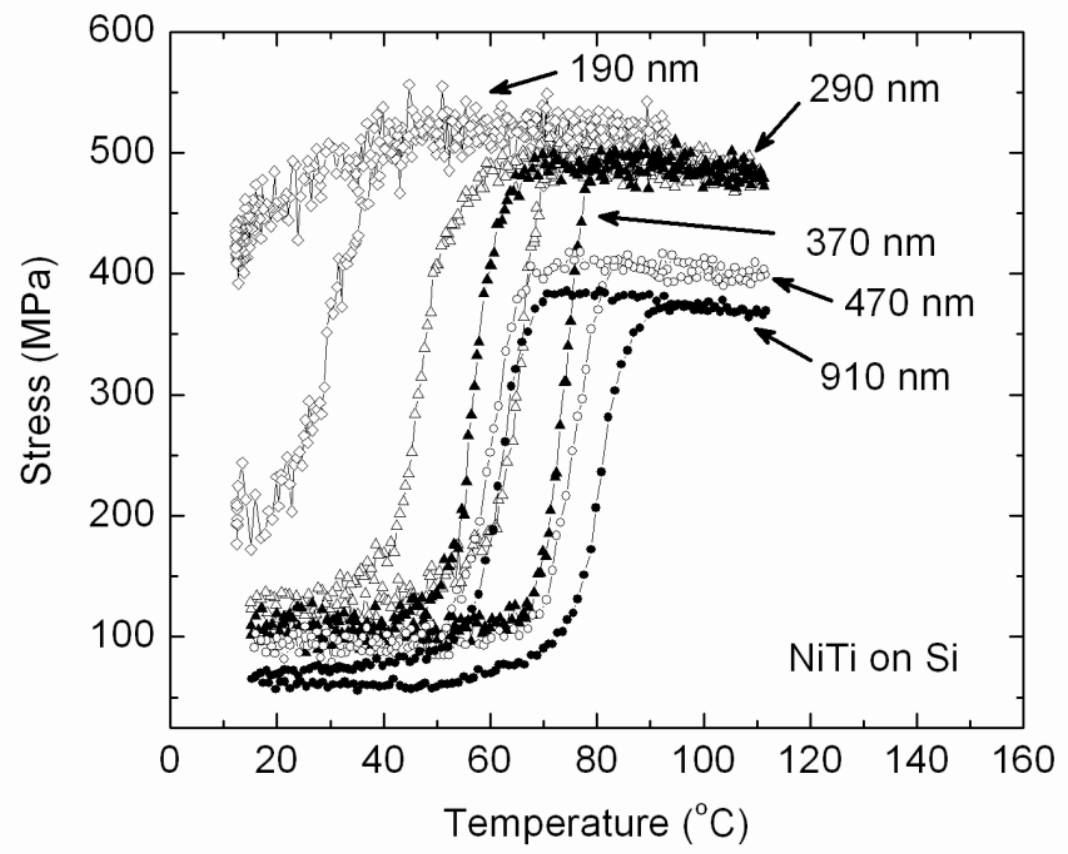

Fig. 4. Stress-temperature curves for the NiTi film stacks on Si substrates. The contribution of the $\mathrm{SiN}_{\mathrm{x}}$ coatings has not been subtracted. 


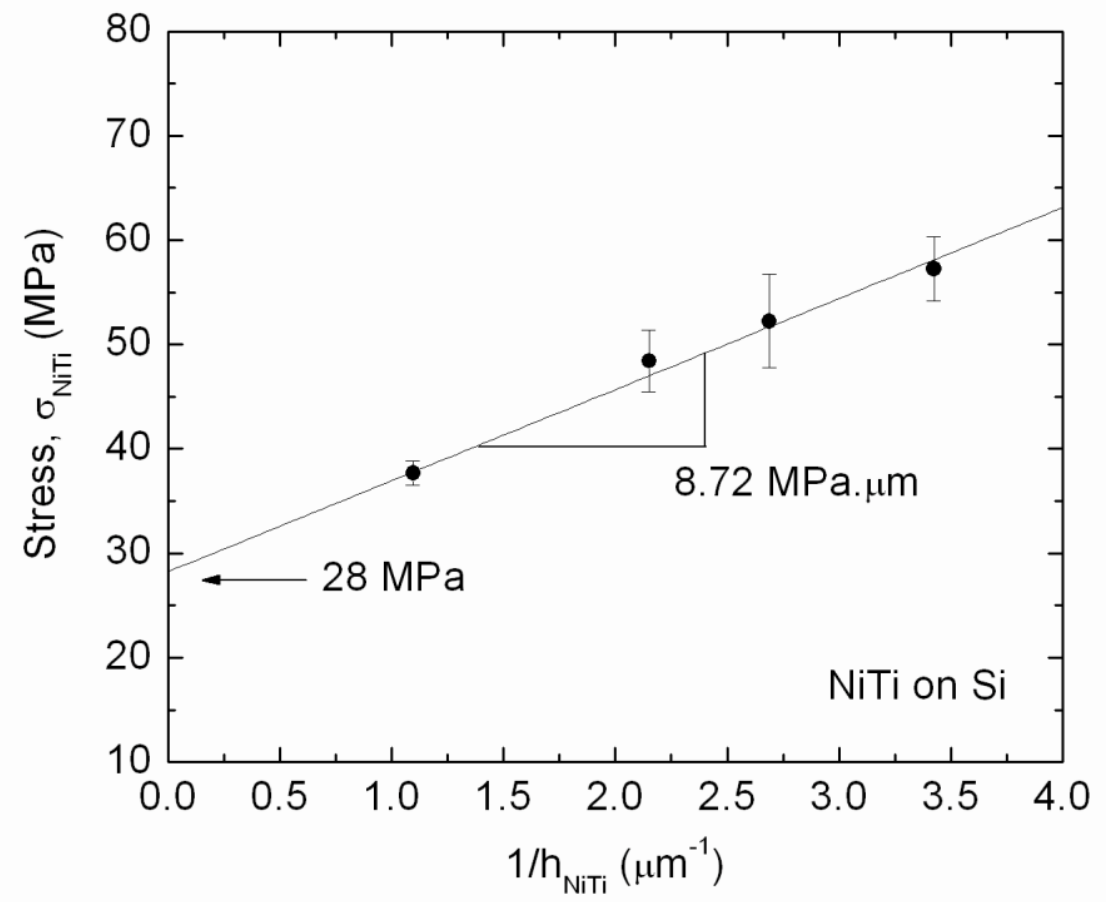

Fig. 5. Film stacks on silicon substrates: Residual stress at room temperature as a function of reciprocal film thickness after subtracting the contributions of the $\mathrm{SiN}_{\mathrm{x}}$ coatings. 


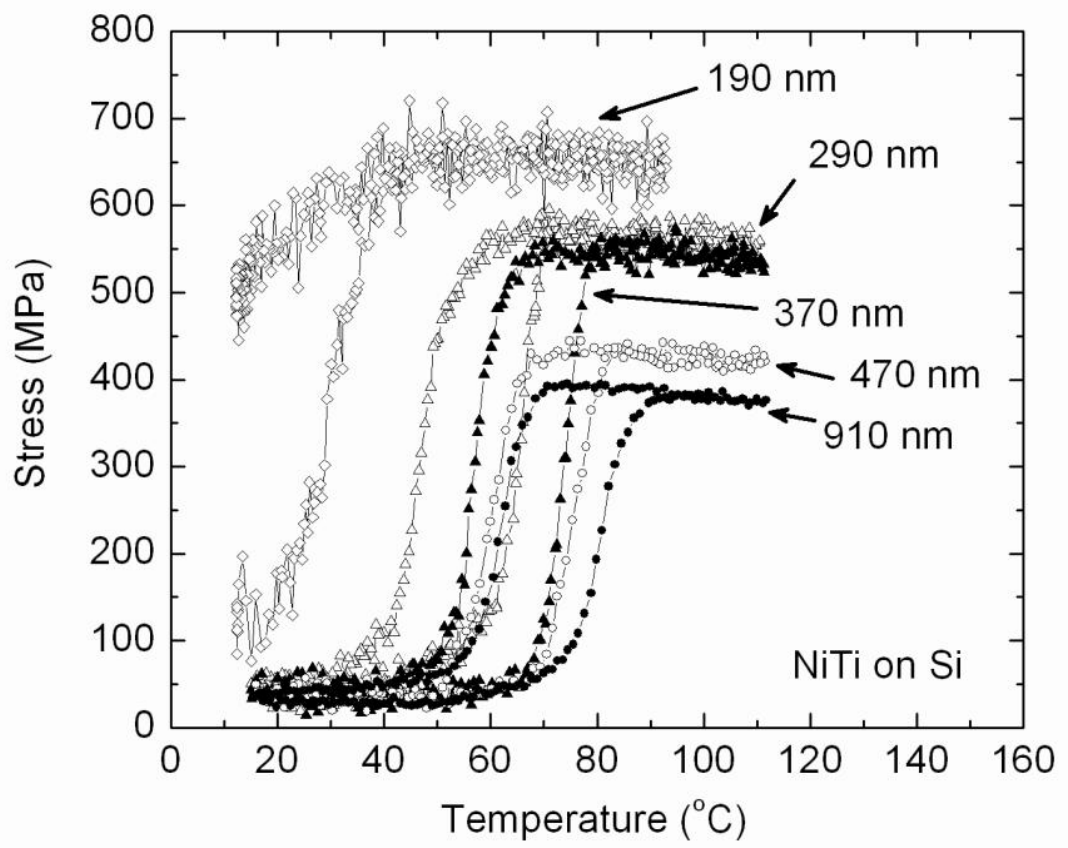

(a)

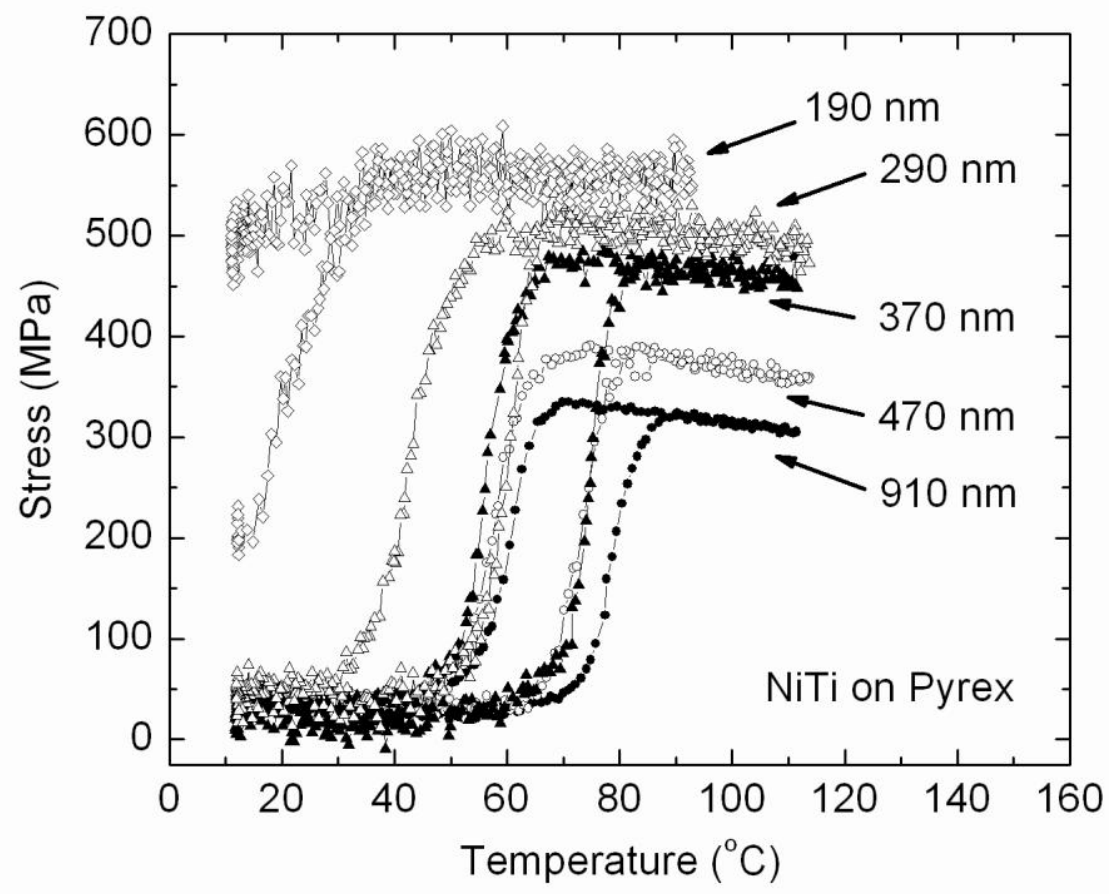

(b) 


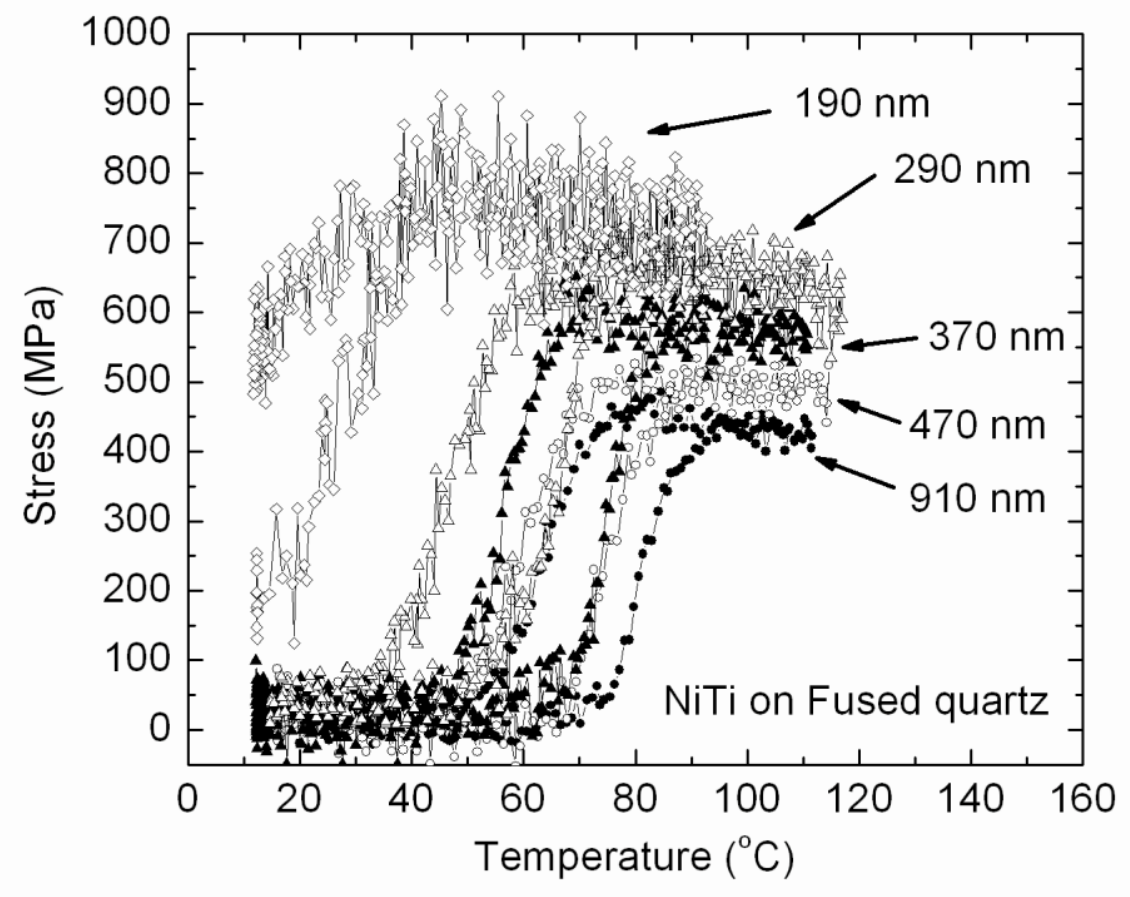

(c)

Fig. 6. Stress in the crystalline layers of the NiTi films as a function of temperature: (a) Films on silicon substrates; (b) Films on Pyrex substrate; (c) Films on fused quartz substrate. 


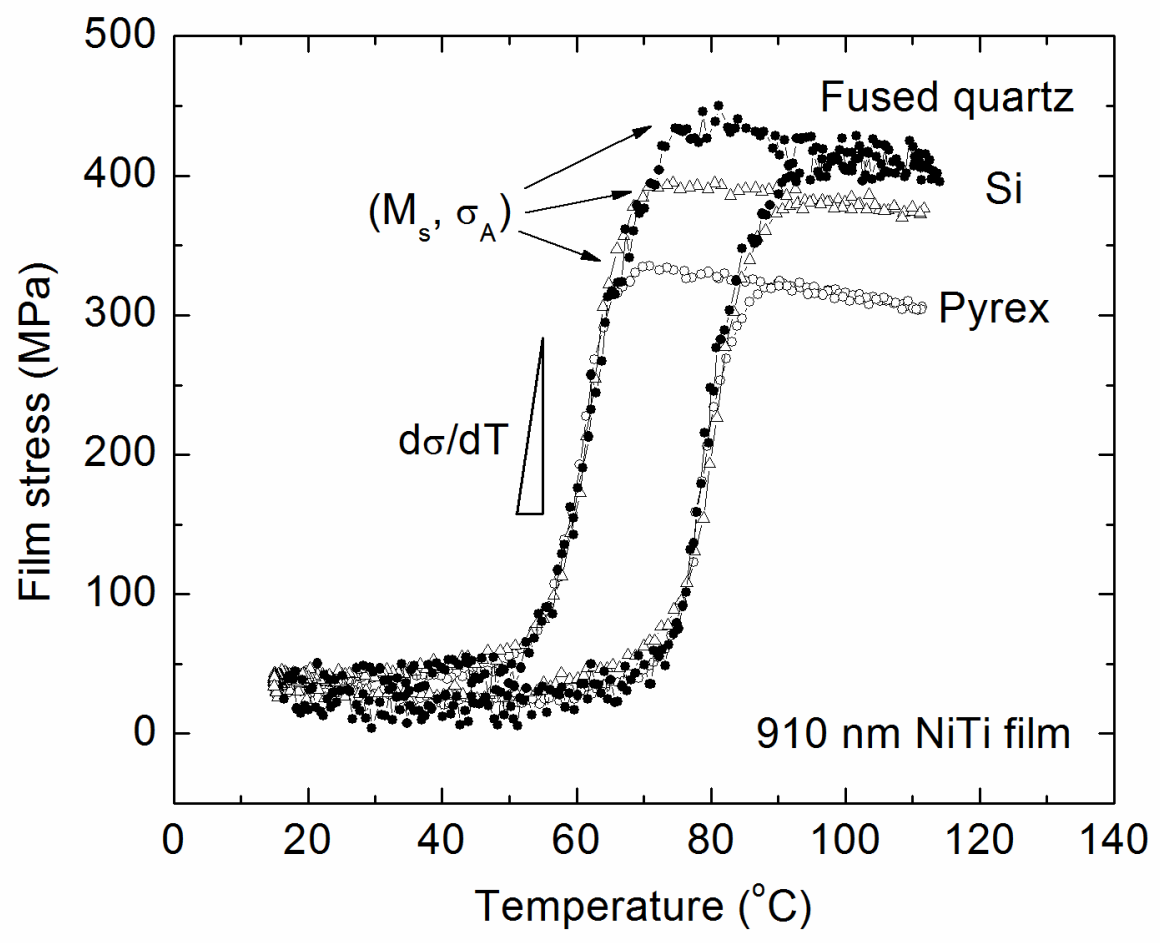

Fig. 7. Film stress in $910 \mathrm{~nm}$ film on different substrates as a function of temperature. 


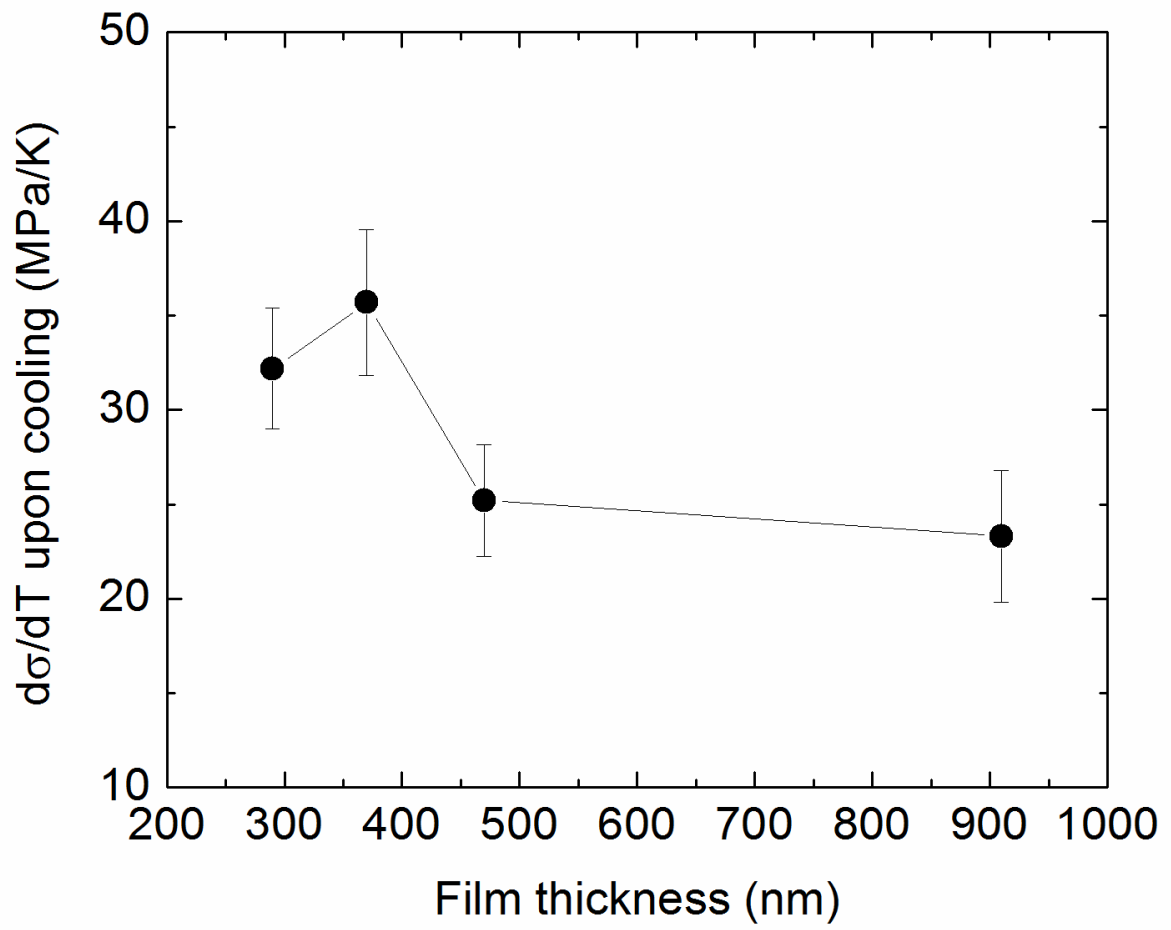

Fig. 8. The slope $\mathrm{d} \sigma / \mathrm{d} T$ of the stress-temperature curve during transformation upon cooling. 


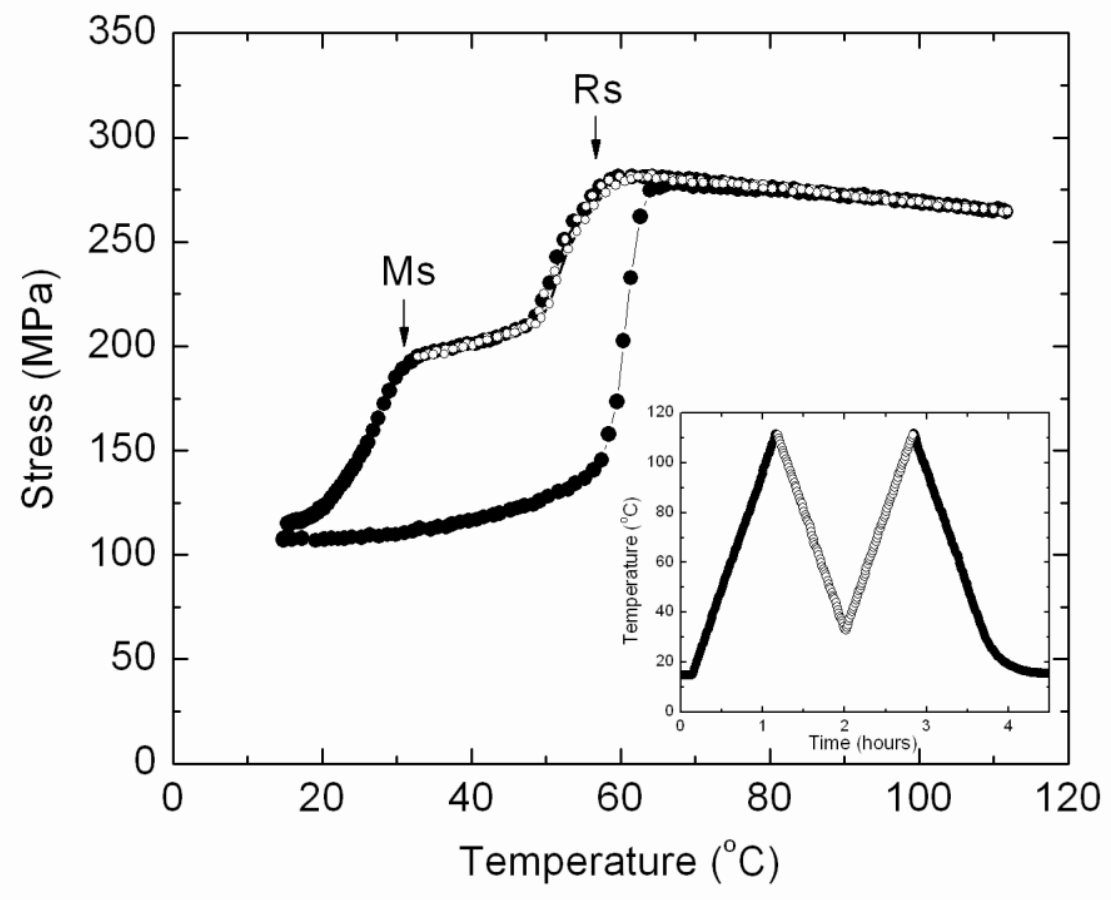

Fig. 9. Stress-temperature curve for a NiTi film on a Corning glass substrate. The inset shows the thermal history in the measurement; open symbols in the inset correspond to open symbols in the stress-temperature curve. 


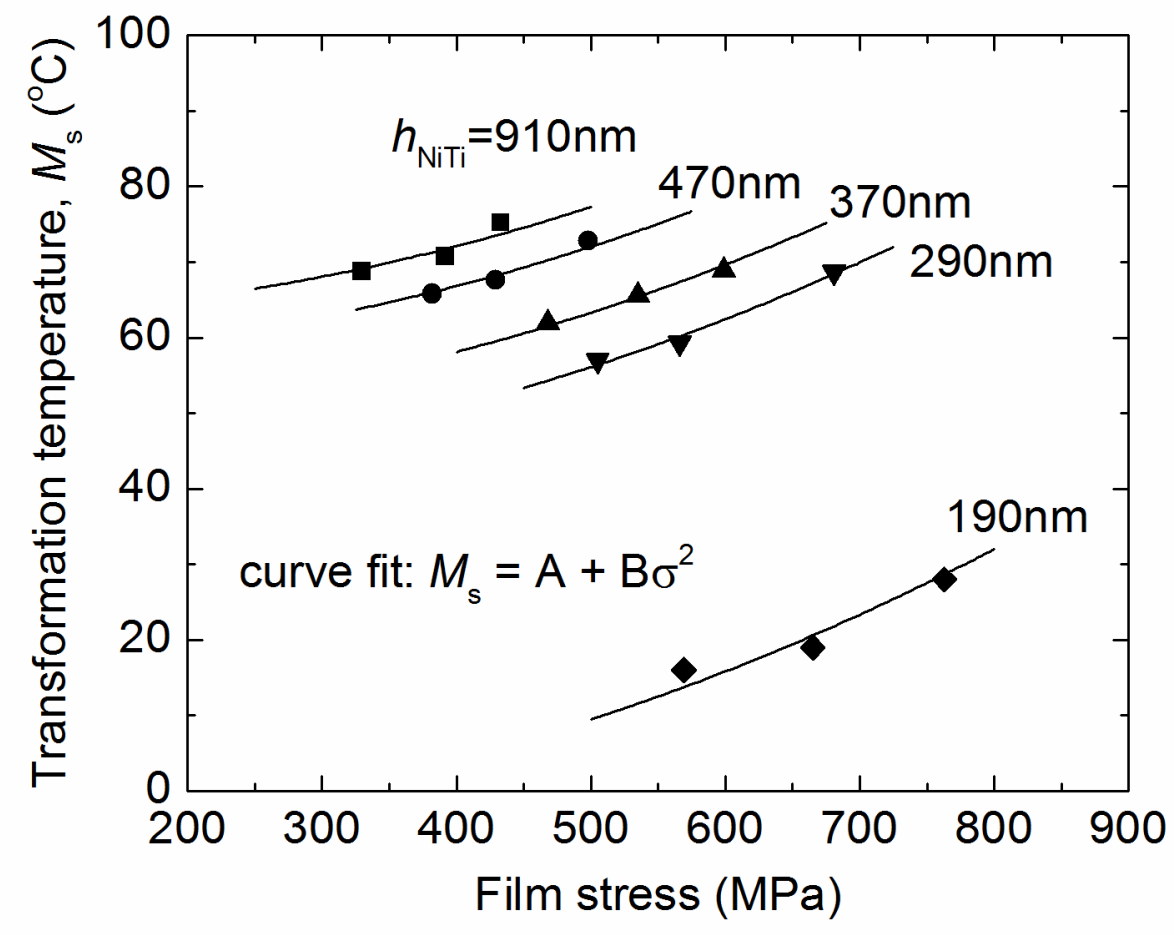

Fig. 10. Transformation temperature as a function of film stress and film thickness. Curve fits are based on Eq. (7) in the text using the same coefficient B for the stress term for all data sets. 


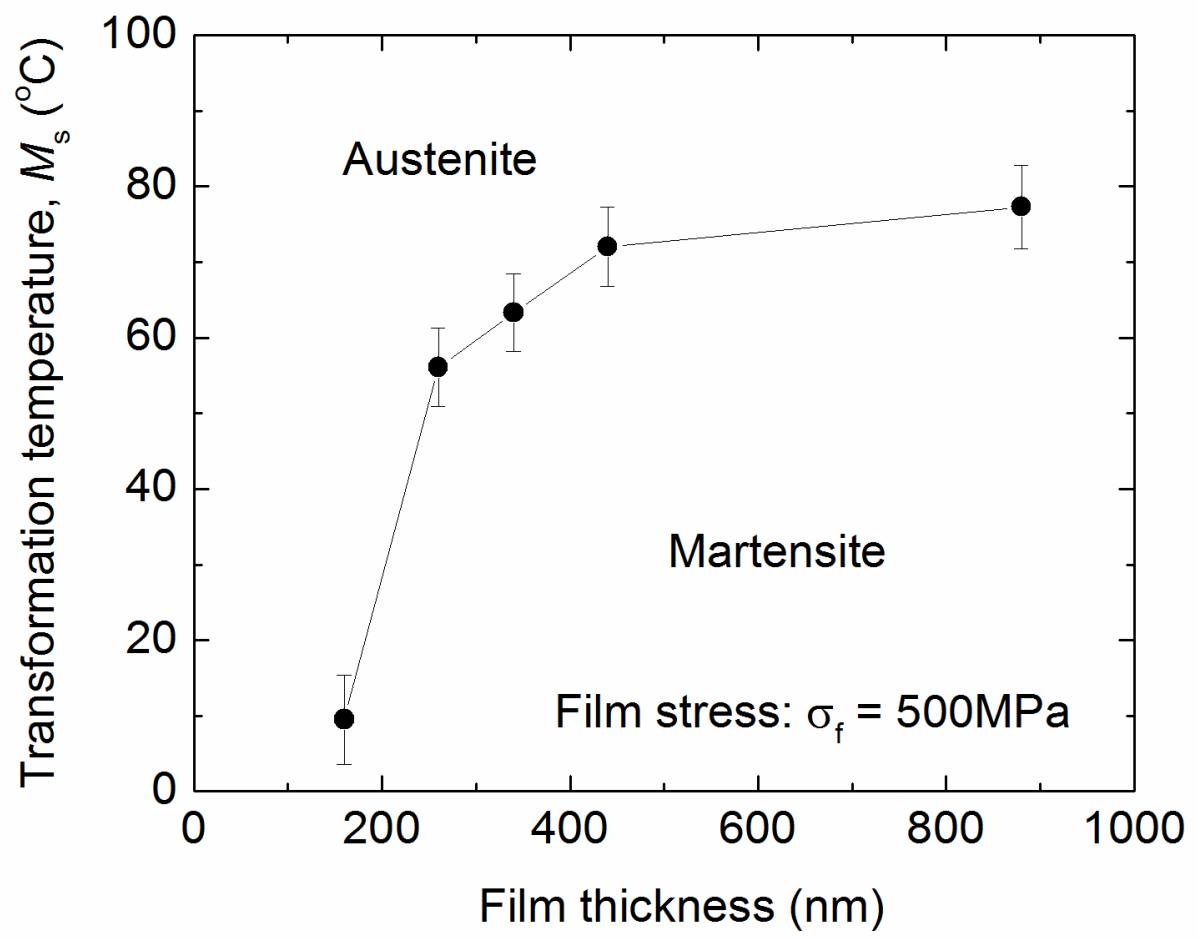

Fig. 11. $M_{s}$ transformation temperature at a film stress of $500 \mathrm{MPa}$ as a function of film thickness. Transformation temperatures were calculated at the reference stress using the curve fits in Fig. 10 . 


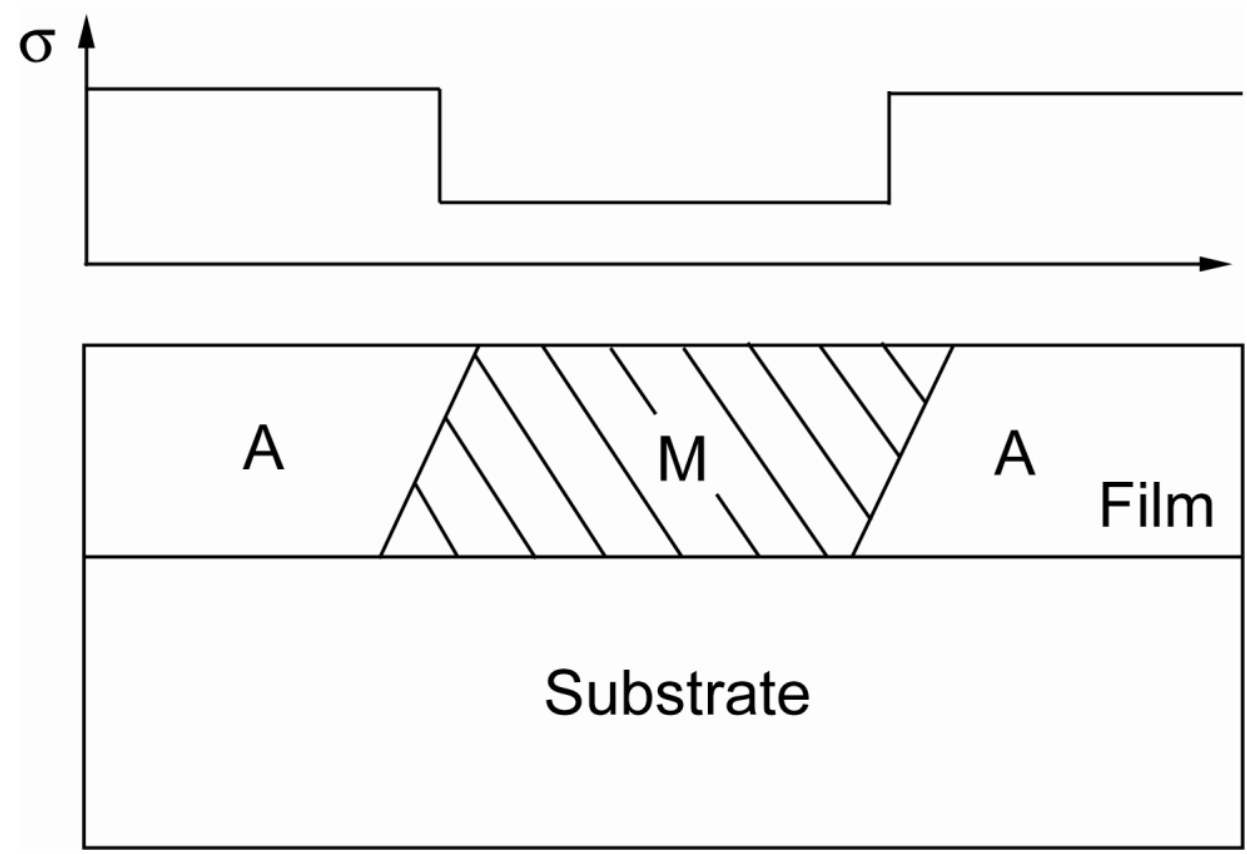

Fig. 12. Stress profile inside the two-phase film. 


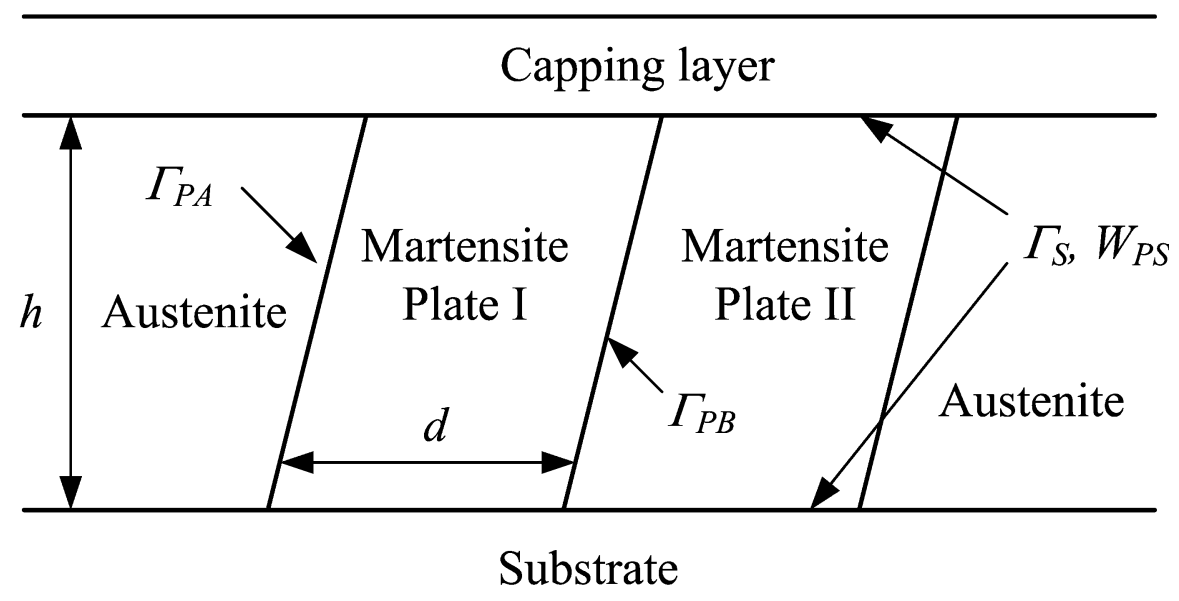

Fig. 13. Energy terms associated with transformation. 


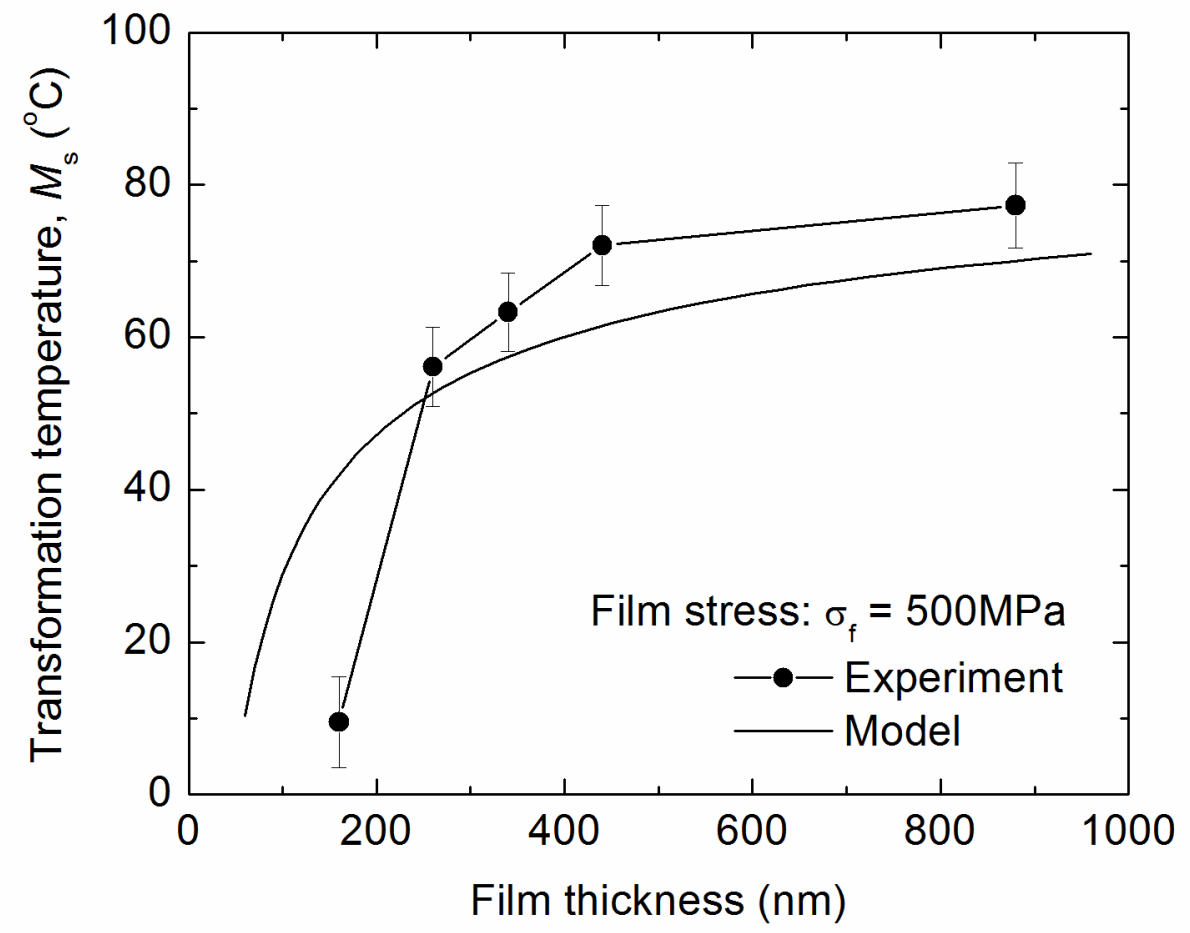

Fig. 14. Comparison of the model with experiment for transformation temperature. 